\title{
A Study on the Design of Vaccine Cooling Boxes for Remote and Border Areas
}

\author{
Imron Rosyadi $^{1 *}$, Haryadi ${ }^{1}$, Dhimas Satria ${ }^{1}$ \\ ${ }^{1}$ Mechanical Engineering Department Universitas Sultan Ageng Tirtayasa Jendral Sudirman Street Km. 3, Cilegon, \\ Banten \\ *Corresponding author. Email: imron_jtm@untirta.ac.id
}

\begin{abstract}
Immunization is an effort to actively generate/increase a person's immunity to a disease, so that if one day they are exposed to the disease, they will not get sick or only experience mild illness. This is done by administering a vaccine into a person's body. Vaccines used to form antibodies have some susceptibility or weakness to damage. Vaccines have the potential to be damaged when exposed to heat and freezing temperatures. Vaccines should be stored at a temperature between 2 oC - 8 oC continuously. Vaccine storage should not reach the freezing temperature of the vaccine so as not to damage the function of the vaccine itself. Often the temperature of the vaccine increases over long journeys, thereby increasing the exposure of the vaccine to heat. This happens a lot when administering vaccines to remote border areas and islands, especially in border areas. The quiet design of vaccine cooler boxes is important by taking into account the ability to maintain room temperature. Factors that must be considered in designing this include insulating materials, electrical equipment and technology indicators, energy storage media discussed here. Parameters that affect tool performance are also discussed. So with this paper we can learn how to design a vaccine box comprehensively to produce a device that meets health standards.
\end{abstract}

\section{Keywords: Vaccine Cooling Box, Remote Area, Freezing Temperatures, Storage System}

\section{INTRODUCTION}

Immunization is an action to provide immunity to a disease by giving a vaccine to the body. The immunity in question is the ability to prevent disease or minimize the effects caused by the disease to a person [1]. This is done by administering a vaccine into a person's body. Vaccines used to form antibodies have some susceptibility or weakness to damage. Vaccines have the potential to be damaged when exposed to heat and freezing temperatures. Vaccines should be stored at a temperature between $2{ }^{\circ} \mathrm{C}-{ }^{\circ} 8 \mathrm{C}$ Vaccine storage should not reach the freezing temperature of the vaccine so as not to damage the function of the vaccine itself. Often the temperature of the vaccine increases over long journeys, thereby increasing the exposure of the vaccine to heat. This happens a lot when administering vaccines to remote border areas and islands, especially in border areas. The quiet design of vaccine cooler boxes is important by taking into account the ability to maintain room temperature. Factors that must be considered in designing this include insulating materials, electrical equipment and technology indicators, solar energy or energy storage media discussed here. Parameters that affect tool performance are also discussed. So with this paper we can learn how to design vaccine boxes comprehensively including the concept of heat transfer, insulation materials, phase change materials, Thermo Electric Cooling (TEC) and optimization of tool performance to produce equipment that meets health standards.

\section{HEAT TRANSFER AND INSULATION}

Heat transfer is the transfer of energy that occurs due to a temperature difference between objects or materials. The energy that is transferred is called heat or heat. In a thermoelectric cooling system, heat transfer occurs by conduction and convection. Conduction heat transfer occurs in the heat sink on the hot side of the peltier and on the heat sink on the cold side of the peltier. Meanwhile convection heat transfer occurs in the air that passes through the heat sink, and the air in the room or test equipment.

Conduction heat transfer occurs when there is a temperature difference between two surfaces separated 
by a solid or fluid. Another requirement of this heat transfer model is that there is no bulk movement of the media, whether it is caused by heat transfer or external equipment. Conduction occurs because of the contact of molecules/particles, and energy moves from molecules/particles that have more energy to particles with lower energy. The average amount of energy that moves per unit time in the conduction process is known as the heat transfer rate $q_{c d}^{\prime}(\mathrm{W} / \mathrm{m} 2)$ we can calculate using an equation known as Fourier's law.

$$
q_{c d}^{\prime}=-k \cdot A \cdot \frac{d T}{d x}
$$

Where $A$ is the area in the direction of displacement $\left(\mathrm{m}^{2}\right)$ and is directly proportional to the temperature gradient $\mathrm{dT} / \mathrm{dx}$ in the same direction of displacement, where $\mathrm{k}$ is the thermal conductivity $\left(\mathrm{W} / \mathrm{m} .{ }^{\circ} \mathrm{C}\right)$. When expressed in heat energy (joules), the equation becomes:

$$
Q_{C D}=k \cdot\left(T_{h}-T_{C}\right)=k \cdot \Delta T
$$

The second heat transfer mode is convection, this heat transfer model takes place between the surface and the medium / fluid that passes through the surface. The movement is not only microscopic as in the conduction heat transfer model, but there is also a macroscopic bulk movement. So that energy transfer takes place through bulk movement of the fluid (advection) and molecular interactions in a natural way or using external equipment such as pumps, blowers, compressors and so on. To calculate the quantity of heat transfer by convection we use an equation known as Newton's law of cooling.

Where:

$$
q_{c v}^{\prime}=h \cdot\left(T_{s}-T_{\infty}\right)
$$

$T_{S}=$ Surface Temperature $\left({ }^{\circ} \mathrm{C}\right)$

$T_{\infty}=$ Fluid Temperature $\left({ }^{\circ} \mathrm{C}\right)$

$\mathrm{h}=$ Convection heat transfer coefficient $\left(\mathrm{W} / \mathrm{m}^{2}{ }^{\circ} \mathrm{C}\right)$

The third is heat transfer mode is radiation. Thermal radiation is energy emitted by a surface at a finite temperature. In the following discussion, the radiation that occurs is focused on solid materials, although emissions may occur in fluids or gases. Radiant energy is carried through electromagnetic waves in contrast to conduction or convection heat transfer which requires a medium, radiation does not. In fact, the radiation energy transfer process is most effective under vacuum conditions.

Radiation always travels at the speed of light, $3 \times 10^{10}$ $\mathrm{cm} / \mathrm{s}$. Thermal radiation propagation takes place in the form of quantum and each quantum contains energy of :

$$
\begin{aligned}
& \mathrm{E}=\mathrm{h} . v, \\
& \mathrm{~h}=\text { konstanta Planck, } 6,625 \times 10^{-34} \mathrm{~J} . \mathrm{s}
\end{aligned}
$$

In the design of the vaccine box, the material selection is divided into 2. Namely, thermal insulation materials and materials for storing heat in the media so that the cooling effect can be longer or better known as Phase Change Material (PCM). Understanding thermal insulation in general is a method or a series of processes used to reduce or reduce the rate of heat energy transfer. The energy as described above can be attenuated in several ways, namely conduction, convection and radiation. The amount of heat energy flowing in a material varies, depending on the nature of the thermal conductivity of the material used.

Table 1. Materials thermal conductivity value

\begin{tabular}{|l|c|}
\hline \multicolumn{1}{|c|}{ Material } & $\mathrm{k}, \mathrm{W} / \mathrm{m} \cdot{ }^{\circ} \mathrm{C}^{*}$ \\
\hline Diamond & 2300 \\
Silver & 429 \\
Copper & 401 \\
Gold & 317 \\
Aluminium & 237 \\
Iron & 80.2 \\
Mercury (I) & 8.54 \\
Glass & 0.78 \\
Brick & 0.72 \\
Water (l) & 0.613 \\
Human skin & 0.37 \\
Wood (oak) & 0.17 \\
Helium (g) & 0.152 \\
Soft rubber & 0.13 \\
Glass fiber & 0.043 \\
Air (g) & 0.026 \\
Urethane, rigid & 0.026 \\
foam & \\
\hline
\end{tabular}

Materials used to reduce the rate of heat transfer are called insulators or insulators [2]. In the process or method, the first step is very important to know the type of insulation so that there are no mistakes in the selection. The ability of a particular solid to conduct heat is called its thermal conductivity or is known as the $\mathrm{k}$ factor. To choose a material that has good insulation, the smallest value of $\mathrm{k}$ is chosen. The following are several types of insulation materials based on their thermal conductivity values.

\section{PCM MATERIAL}

Phase Change Material (PCM) is generally widely used in cooling systems. This material has a high melting heat, melts and freezes at a certain temperature and has the ability to emit or generate high enough energy. The melting point of $\mathrm{PCM}$ ranges from $-33{ }^{\circ} \mathrm{C}$ to $101{ }^{\circ} \mathrm{C}$ with 
the use of TEA-16, ethylene glycol, n-Dodecane, and water to protect the freshness of products such as fruit, fish, meat or vaccines with melting points ranging from -16 ${ }^{\circ} \mathrm{C},-11.5{ }^{\circ} \mathrm{C},-9.6{ }^{\circ} \mathrm{C}$, and $0{ }^{\circ} \mathrm{C} \quad$ [3].

Materials consist of 3 states, namely solid, liquid and gas, which requires latent heat to change its state. Phase change material is one type of thermal energy storage that is able to maintain temperature for a certain period of time. The external heat is used to break the internal lattice bonds of the PCM material, thus it absorbs a large amount of latent heat at the phase temperature. When the PCM temperature drops below the phase change temperature (sub cooling or under-cooling), this state can be used as a nuclear shield for phase change. Phase reversal begins at the phase change temperature by releasing latent heat back into the environment when conditions are under sub-cooling. For this reason the requirement of sub-cooling conditions for phase change is an important property of PCM [4]. Figure 1 presents a working phase change scheme of matter in a solid-liquid PCM example.

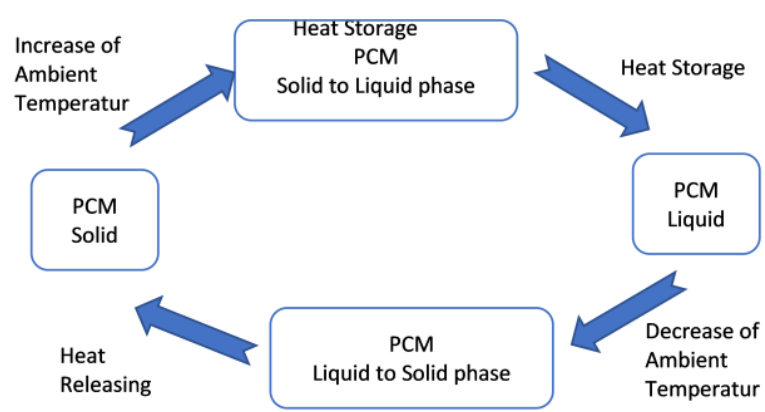

Figure 1. Phase change material working scheme [5]

Latent heat is a property of a substance that is required to change phases at a constant temperature. PCM is a reliable material in terms of latent heat properties because it has the capability of 2-3 times as sensible heat at a temperature of $20 \mathrm{oC}$ per unit volume or mass of material. In general, these materi-als can be classified into 3 major groups, namely in-organic PCM materials, organic PCMs, and eutectic PCMs, each of which has different types and charac-teristics with advantages and disadvantages [6][7][3][8][9][10][11]. In Figure 2 in more detail you can see the branching of several types of PCM that are commonly used in the market and have been mass produced and engineered to improve their material properties in many current studies.

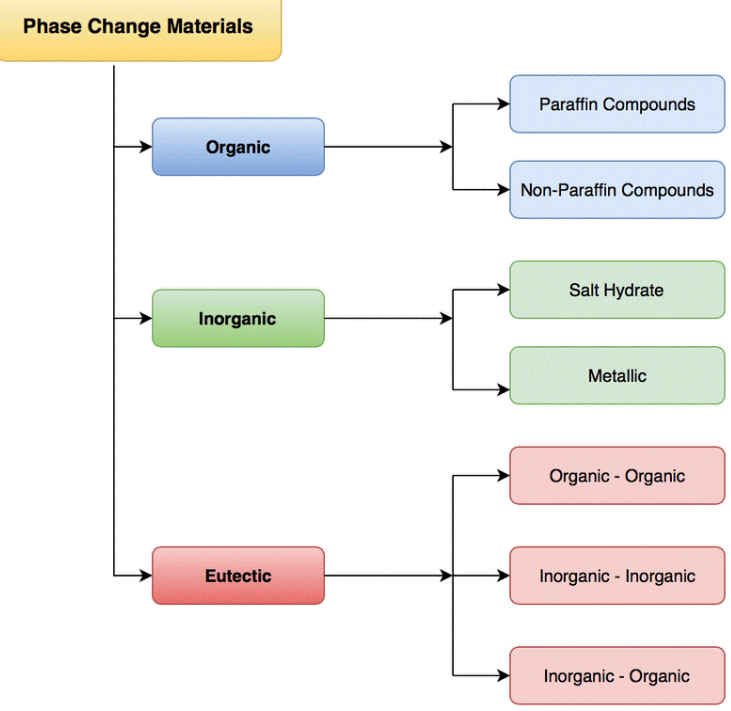

Figure 2. Phase change Material Classification Solidliquid material PCM is best suited for thermal energy storage.

Solid-liquid PCM consists of organic PCM. A comparison of these different types of PCM is listed in Table 2.

Table 2. Comparison of various types of PCM [8]

\begin{tabular}{|c|c|c|}
\hline $\begin{array}{l}\text { Classi- } \\
\text { fication }\end{array}$ & Advantages & Disadvantages \\
\hline $\begin{array}{l}\text { Or- } \\
\text { ganic } \\
\text { PCMs }\end{array}$ & $\begin{array}{ll}\text { 1. } & \text { Availability in a } \\
\text { large temperature } \\
\text { range }\end{array}$ & $\begin{array}{l}\text { 1. Low thermal } \\
\text { conductivity } \\
\text { (around } 0.2 \\
\mathrm{~W} / \mathrm{m} \mathrm{K} \text { ) } \\
\text { 2. Relative } \\
\text { large volume } \\
\text { change } \\
\text { 3. Flammability }\end{array}$ \\
\hline $\begin{array}{l}\text { In Or- } \\
\text { ganic } \\
\text { PCMs }\end{array}$ & $\begin{array}{l}\text { 1. High heat of fusion } \\
\text { 2. High thermal con- } \\
\text { ductivity (around } \\
0.5 \mathrm{~W} / \mathrm{m} \mathrm{K} \text { ) } \\
\text { 3. Low volume } \\
\text { change } \\
\text { 4. Availability in low } \\
\text { costEutectics }\end{array}$ & $\begin{array}{l}\text { 1. Supercool- } \\
\text { ing } \\
\text { 2. Corrosion }\end{array}$ \\
\hline $\begin{array}{l}\text { Eutec- } \\
\text { tics }\end{array}$ & $\begin{array}{l}\text { 1. Sharp Melting tem- } \\
\text { perature } \\
\text { 2. High volumetric } \\
\text { thermal storage } \\
\text { density }\end{array}$ & $\begin{array}{l}\text { Lack of currently } \\
\text { available test } \\
\text { data of thermo- } \\
\text { physical proper- } \\
\text { ties }\end{array}$ \\
\hline
\end{tabular}


Table 3. Comparison between the different methods of heat storage [17].

\begin{tabular}{|l|c|c|c|c|}
\hline \multicolumn{1}{|c|}{ Property } & Rock & Water & Organic PCM & Inorganic PCM \\
\hline Density, kg/m³ & 2240 & 1000 & 800 & 1600 \\
Specific heat, kJ/kg & 1.0 & 4.2 & 2.0 & 2.0 \\
Latent heat, $\mathrm{kJ} / \mathrm{kg}$ & - & - & 190 & 230 \\
Latent heat, $\mathrm{kJ} / \mathrm{m}^{3}$ & - & - & 152 & 368 \\
Storage mass for $106 \mathrm{~J}, \mathrm{~kg}$ & 67,000 & 16,000 & 5300 & 4350 \\
Storage volume for $106 \mathrm{~J}, \mathrm{~m}^{3}$ & 30 & 16 & 6.6 & 2.7 \\
Relative storage mass & 15 & 4 & 1.25 & 1.0 \\
Relative storage volume & 11 & 6 & 2.5 & 1.0 \\
\hline
\end{tabular}

\subsection{PCM Thermal Stability}

PCM requires good stability in latent heat storage. Changes in the thermal properties of the PCM should not be too large after the thermal cycle occurs. Many studies have been carried out on the stability of PCM for salt hydrates, organic mixtures, inorganic mixtures [12][13][14].

From several researchers, it was found that potential PCM data were identified as having good stability and thermo-physical properties. As, Shukla et al [15] who tested the thermal cycle on several organic and inorganic PCMs where this test was based on physics, chemistry, thermal and kinetic as shown in Table 3. From several existing research results it can be shown that organic PCM has better thermal stability than inorganic PCM.

Research on the properties of melting temperature and heat of smelting for calcium chloride hexahy-drate material on the thermal cycle has been carried out by Tyagi and Buddi [16], but the results of these studies do not show a significant thing, only $1-1.5 \mathrm{C}$ or about $4 \%$ in every 1000 thermal cycles. However, Calcium chloride hexahydrate is also recommended as a PCM that has a good future for application in various industries for thermal engineering.

\subsection{Application of Commercial PCM}

In its application, PCM is widely used for needs such as air conditioning, absorption refrigeration, vaccine boxes or fresh food storage, dispensers that use cooling technology, HVAC systems or several other thermal applications that require cold and hot properties of the material. Melting point properties are very important to note in the use of PCM, for air conditioning applications, fresh food storage is at temperatures below $15^{\circ} \mathrm{C}$. while for the application of the vaccine box, the melting point of PCM is around $4-6^{\circ} \mathrm{C}$, while materials with temperatures above $90{ }^{\circ} \mathrm{C}$ are used for absorption refrigeration systems [7].

Commercial paraffin wax has a medium thermal storage density, which is around $150 \mathrm{MJ} / \mathrm{m} 3$ or equivalent to $200 \mathrm{~kJ} / \mathrm{kg}$ with a good melting tempera-ture range as shown in the figure. 3a. Subcooling or known as undercooling is a property in which the liq-uid phase is at a temperature below its normal boiling point. In PCM material, the properties of the material under subcooling conditions are very good or stable in its chemical or physical properties. However, the thermal conductivity can be said to be quite low, which is below $0.2 \mathrm{~W} / \mathrm{m} \mathrm{C}$. The nature of this PCM in its application becomes more limited, for that Hasnain [17] tried to develop PCM material as an energy storage medium by adding a metal filler metal matrix on the tube / heat pipe to increase the rate of heat transfer.

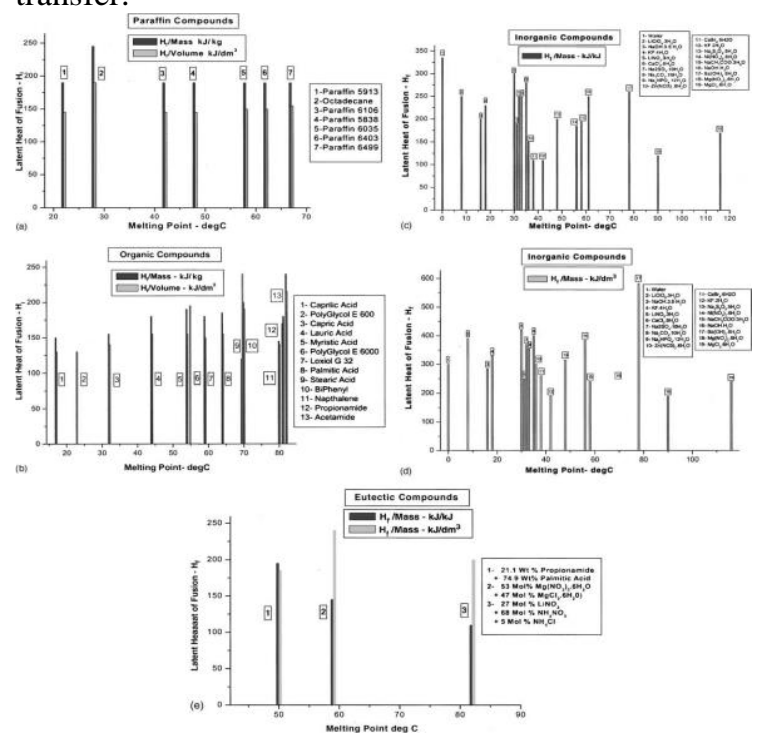

Figure 3. Latent heat of some materials

Thermoelectric is a semiconductor material that has been developed since the 1950s with Bi2Te3 as the base material. This material is then well known in the community and then commercialized into mass products produced by large industries. [18].

This thermoelectric device is not only used for cooling system applications, but can also be converted into a power plant or its known as the "Seebeck effect" which became known in 1821, in the sense that this material has 
been known and has been developing for 2 centuries. When there was a temperature difference on the 2 sides of the hot and cold material surface of the semiconductor material, an electric voltage occurs which was known as the Seebeck voltage. The Seebeck effect is the opposite of the Peltier effect, which uses electrical energy to cool the material. Both of these functions in development are applied in various fields according to needs. In air conditioning applications, this thermoelectric is quite effective in cooling the room with a much lower electrical power consumption than a vapor compression cooling system [19].

The thermoelectric construction consists of a pair of p-type and n-type semiconductor materials that form a thermocouple. This module can be used to generate heat and cold on each side if an electric current is used normally applied as a cooling system [19], [20], for example vaccine cooler boxes [21], [22], [23],[24] or to generate electricity when hot and cold are used as the temperature difference [19], [25].

\subsection{Performance Modul Termoelectrik}

To find the performance of the thermoelectric module, it is presented with the equation can be written as below.

$$
Q_{s b}=\alpha \cdot I . T_{c}
$$

The symbol alpha $\alpha$ is the average Seebeck coefficient of the thermoelectric material. From this equation we can see the relationship between the rate of heat transfer that is dissipated when flowing with the current. Thermal energy in Joules: The flow of current I produces resistive heating or Joules $\left(Q_{J}\right)$ in a thermoelectric material. This energy is then divided into two, namely Joule heat towards the cold end of $50 \%$ and another $50 \%$ towards the hot end. Joule heating is given by equation (6) below:

$$
Q_{J}=I^{2} \cdot R
$$

With the substitution method in Equations (2), (5) and (6) and combined with the energy balance equation for the hot and cold sides of the thermoelectric, equation (7) will be obtained.

$$
\begin{aligned}
& Q_{c}=Q_{s b}-0.5 \cdot Q_{J}-Q_{C D J}=\left[\alpha . I . T_{c}\right]- \\
& 0.5\left[I^{2} \cdot R\right]-\left[k \cdot A \cdot \frac{\Delta T}{d x}\right]
\end{aligned}
$$

Hence to calculate the energy consumption in this thermocouple pair, the equation is :

$$
Q_{E}=I^{2} \cdot R+\alpha \cdot I \cdot \Delta T
$$

In equation (8) it is known that if the amount of heat is $50 \%$ of $\mathrm{QJ}$ and the heat of conduction (Qcd) is equal to the Peltier heat (Qsb) then the thermoelectric module can be considered inoperative or $\mathrm{Qc}=0$. So the COP of the thermoelectric module for the cooling process is:

$$
\varepsilon=Q_{c} / Q_{E}=\frac{\left[\alpha \cdot I \cdot T_{c}\right]-0.5\left[I^{2} \cdot R\right]-\left[k \cdot A \cdot \frac{\Delta T}{d x}\right]}{I^{2} \cdot R+\alpha \cdot I \cdot \Delta T}
$$

The magnitude of the optimum (maximum) current at the COP can be written as follows:

$$
\begin{aligned}
& I_{o p t} \\
& =\frac{\alpha \cdot \Delta T / R}{\sqrt{1+Z . T m}-1}
\end{aligned}
$$

If the magnitude of the current I is replaced with the optimum current $I_{\text {opt }}$ then the magnitude of the optimum COP can be written

$$
\begin{aligned}
& \varepsilon_{\text {opt }} \\
& =\frac{T_{c}}{T_{h}-T_{c}} \frac{\sqrt{1+Z . T m}-\frac{T_{h}}{T_{c}}}{\sqrt{1+Z . T m}+1}
\end{aligned}
$$

Parameters that show the relationship between $\mathrm{Z}$ (Seebeck coefficient), $\mathrm{R}$ (electrical resistivity) and $\mathrm{k}$ (thermal conductivity) are indicated by dimensionless numbers by multiplying by $\mathrm{T}$ (the average temperature of the hot side and cold side of the thermoelectric module, K).

$$
Z T=\frac{\alpha^{2} \cdot T}{k \cdot R}
$$

\subsection{Development Of Thermoelectric Materials}

Phonon-glass electron-crystal (PGEC) is known to have good electronic properties, usually associated with single-crystal semiconductors but will have thermal properties like amorphous materials. Several researchers [26][27] have investigated this PGEC material at the nanoscale, where a bulk free electron is charged with carrying heat which in the process is disturbed for the transport of heat

Today's main thermoelectric materials are generally doped, including clarates, skutterudites, and halfHesler alloys. Low-dimensional materials with 0-2 D quantum wells process the quantum confinement effect of electron charge-carrying atoms into an increase in the Seebeck coefficient and power factor. In this nanomaterial, the multiple interfaces of the material can scat 
Table 4. Thermoelectric materials, figure of merit and its temperature operation

\begin{tabular}{|l|c|c|c|c|}
\hline \multicolumn{1}{|c|}{ Material } & Type & ZT value & Temperature & Ref \\
\hline Bi-doped PbSeTe/PbTe (QDSL) & n-type & 3 & $550 \mathrm{~K}$ & {$[6]$} \\
In 0.2Ce0.15Co4Sb12 Skutterudite & n-type & 1.43 & $800 \mathrm{~K}$ & {$[7]$} \\
Pb0.25n0.25Ge0.5Te & p-type & $\sim 0.95$ & $670 \mathrm{~K}$ & {$[8]$} \\
(Bi0.25Sb0.75)2Te3 & p-type & 1.27 & $298 \mathrm{~K}$ & {$[9]$} \\
Bi2(Te0.94Se0.06)3 & n-type & 1.25 & $298 \mathrm{~K}$ & {$[9]$} \\
K0.95Pb20Sb1.2Te22 & n-type & $\sim 1.6$ & $750 \mathrm{~K}$ & {$[10]$} \\
PbTeeSrTe & p-type & 1.7 & $\sim 800 \mathrm{~K}$ & {$[11]$} \\
Binary crystalline In4Se3_d & n-type & 1.48 & $\sim 705 \mathrm{~K}$ & {$[12]$} \\
AgPbmSbTe2bm & n-type & $\sim 2.2$ & $800 \mathrm{~K}$ & {$[13]$} \\
\hline
\end{tabular}

ter phonons effectively. As a result, the thermal conductivity of the material will decrease more than the resulting electrical conductivity [18].

The best commercial thermoelectric materials currently have a ZT value of about 1.0. The highest $Z T$ value in the study was around 3, reported by Harman in 2005 [28]. The maximum efficiency of the thermoelectric material is determined by the thermoelectric figure of merit or known as ZT. The best thermoelectric material has a figure of merit value of $1.2-2.2$ in the temperature range of 600-800 K, as shown in Table 4, Bi-doped PbSeTe/Te is a material with the highest figure of merit, which is 3 .

According to Disalvo [29] a ZT value of 1.0 is considered to have a Carnot efficiency close to $10 \%$. While the highest Carnot efficiency in the use of thermoelectric is equivalent to a figure of merit 4.0. However, the value of ZT 4.0 is certainly not an easy challenge [29].

\section{DISCUSSION}

In the design of a cooling system using thermoelectric, it is important to pay attention to the operating power output of the appliance as well as the amount of cooling COP by considering the performance of the thermoelectric module and the design of the heat sink. So finalization Therefore, in fact, the design of the thermoelectric cooling system from the design of the cooling system in the end is optimization to get minimum power with maximum COP. This has practically become the standard used by a designer to design a cooling system using thermoelectric. There are 3 things that need to be considered in designing a thermoelectric-based cooling system. First, the dimensions and geometry of the thermoelectric module such as length, surface area, flatness, length and area ratio, slenderness ratio and number of elements are very important in designing thermoelectric systems. Second, the placement and number of thermocouples, the quality of the thermal paste (thermal contact resistance), the selection of the type of heat sink, the surface area of the heat sink, the ability of the heat sink to transfer heat is also important. voltage, selection of electric power storage (battery), series and parallel installation methods are also important to note and the cooling mass flow rate with the selection of fans, water tubes material as cooling media and mass flow rate of cooler fluid are also things that need to be considered and greatly determine the performance of the system. Several methods were adopted by several [30]) to optimize the design with the genetic algorithm method by optimizing the physical properties of the thermoelement. Meanwhile [31] tried to do tests with variations in dimensions, geometry and number of thermoelectric elements presented with a graphical approach that is easy to understand by users. Lee, 2013 presented a thermodynamic analysis with an approach through temperature analysis, the entropy shown in the cooling cycle of the thermoelement. A dimensionless analysis method with the aim of reducing the optimal design parameters has been carried out, as well as an entropy analysis based on thermal conductance to evaluate the external irreversibility of the thermoelectric cooling system by combining the first and second laws of thermodynamics. [32] also developed a new dimensional group to represent several important parameters for designing thermoelectric cooling systems such as thermal conduction ratio, conduction convection ratio, and load resistance ratio.

The heatsink basically works by transferring heat from the thermoelement component to the free air. The temperature of the thermoelements is maintained at atmospheric temperature, so that the increase in the thermoelements can be removed as large as possible to produce a large temperature difference on the hot and cold sides. The difference in temperature and construction causes the power generation potential. In a single thermoelectric module to be different characteristic depending on the size. If the temperature difference is getting bigger on the hot side and the cold side, the module will produce a larger voltage and current. A number of thermoelements in the installation can be connected in series or parallel to produce the 
desired voltage or electric current. Several types of thermoelements on the market, the average voltage produced by each thermoelement module ranges between $1-2 \mathrm{~V}$ DC and even up to $5 \mathrm{~V}$ DC depending on the temperature delta variation, but generally one thermoelectric module produces 1.5-2V DC [33].

The development of the use of nanofluids as a medium for increasing the heat transfer coefficient has also been carried out by several researchers resistance [34][35] where the results of these studies show that there is a better potential in maintaining thermal resistance and stability.

The performance of the heat sink on the hot side is more important than the heat sink on the cold side because the heat flux density on the hot side is higher. The pattern of placement and dominance of the heat transfer areas on the hot and cold sides is very important. It is also linear with the value of the heat transfer coefficient which needs to be optimized on which side. For thermoelectric modules with a certain cooling capacity, there is an optimal allocation ratio to achieve maximum COP. Some typical allocation ratios are around $0.36-0.47$.

Energy balance modeling of thermoelectric refrigeration systems can be used in many thermoelectric refrigeration applications such as refrigeration of electronic devices (dispensers, vaccine storage boxes etc.) and air conditioners.

In the numerical studies that have been carried out on p-type and n-type thermoelements, there are different values of electrical conductivity, Seebeck coefficient and thermal conductivity in one thermoelectric module, to some extent. However, this difference is small enough that it can be ignored. Therefore, only a set of Seebeck coefficients, electrical and thermal conductivity will be used in the simulation. Modeling temperature changes across all thermo elements to capture module performance is complex and time consuming. Energy balance models or compact models can be applied to simplify the numerical study process, especially for modeling systems including heat sinks on the hot and cold sides.

In the study of the relationship between the Thomson effect on the Seebeck coefficient, it is concluded that these parameters are influenced by temperature. The value of the Thomson coefficient can improve the thermoelectric cooling performance by about 5-7\% [36], If the Thomson coefficient is negative, the cooling performance will decrease [32]. In commercial thermoelectric coolers on the market the Thomson effect is small and can be neglected. [37] . In the development of the Thomson cooler concept and the equivalent $\mathrm{ZT}$ approximation a higher hot/cold side temperature difference can be achieved in traditional Peltier coolers.

The coefficient of performance and cooling capacity depend on the length of the thermoelement. This dependence is seen in the decrease in the length of the thermoelement. If other parameters (such as crosssectional area) of the thermoelement are constant, then in general, a longer thermoelement length helps to achieve a larger Coefficient Of Performance, and a shorter thermoelement length results in a greater cooling capacity. Most commercially available thermoelectric modules have a thermoelement length range from. 1,0 . $10^{3} \mathrm{~m}$ to $2,5 \cdot 10^{3} \mathrm{~m}$. There is an increase in cooling power density when the ratio of the length of the thermoelement to the cross-sectional area decreases.

The thermal contact resistance at the interface layer of the thermoelement affects the thermoelectric cooling capacity and its COP. An increase in the ZT of a thermoelectric material does not usually result in an increase in the ZT of a thermoelement during the presence of an interface layer [38].

For a given hot and cold side fluid temperature, there is an optimal cooling capacity leading to the maximum COP [39]. Analisis tanpa dimensi adalah alat yang ampuh untuk mengevaluasi kinerja sistem pendingin termoelektrik. Dimensionless analysis is a powerful tool for evaluating the performance of thermoelectric cooling systems. New dimensionless parameters, such as dimensionless entropy generation number [40].

The process and proper installation method play a very important role in providing high-quality thermoelectric modules, and selecting the appropriate module parameters. Current applications of thermoelectric cooling can be categorized into five application areas. First, in the civil market, thermoelectric refrigeration devices are used to cool household appliances such as domestic and portable refrigerators, portable ice boxes, beverage can coolers and picnic baskets. Second, this technology is also applied to medical, laboratory and scientific applications. cooling equipment for laser diodes or integrated circuit chips. Third, thermoelectric refrigeration devices have attracted great attention for heat dissipation in industrial refrigeration and temperature control electronic devices. All four applications can be found in the automotive industry, such as car mini refrigerators, thermoelectric coolers/heaters in car seats. The last is the use of this technology for domestic thermoelectric air conditioning systems [22], [41], [42], [43]. 


\section{CONCLUSION}

This paper presents the design optimization of cooling box devices using Thermoelectric Cooling which is well known today. The heatsink is a new dimension parameter introduced in this thermoelectric technology. Design optimizations include power output for cooling and Coefficient of Performance which is simultaneously related to the external load resistance and geometry of the thermoelectric element. Several parameters that affect the thermoelectric design include thermal conductivity, convection heat transfer coefficient, the amount of cooling load, efficiency and the desired ambient temperature and operating temperature. Design optimization is achieved at a high coefficient of merit and has an effect on the coefficient of performance (COP).

This paper also discusses the development of thermoelectric cooling in the material aspect, its modeling and application. Advances in thermoelectric materials through nanotechnology allow for a significant increase in the ZT factor.

This paper also discusses the potential of PCM, where it also offers opportunities for the development of innovative materials by combining energy storage with other functional attributes.

There are three ways to improve performance in the selection of the thermoelectric model, namely first through good design and optimization of the thermoelectric module, Second, namely the design and optimization of the cooling system, third, improving the working conditions of the thermoelectric cooling system.

\section{REFERENCES}

[1] Kemenkes, Buku profil kesehatan Indonesia. Indonesia. Kementerian Kesehatan RI. Sekretariat Jenderal, 2014.

[2] D. Bergman, Lavine, Incropera, Introduction to Heat Transfer (sixth edition). New York: Wiley, 2011.

[3] A. Sharma, V. V. Tyagi, C. R. Chen, and D. Buddhi, "Review on thermal energy storage with phase change materials and applications," Renew. Sustain. Energy Rev., vol. 13, no. 2, pp. 318-345, 2009, doi: 10.1016/j.rser.2007.10.005.

[4] F. Kuznik, J. Virgone, and J. Noel, “Optimization of a phase change material wallboard for building use," Appl. Therm. Eng., vol. 28, no. 11-12, pp. 1291-1298, 2008, doi: 10.1016/j.applthermaleng.2007.10.012.

[5] M. Kuta, D. Matuszewska, and T. M. Wójcik, "Reasonableness of phase change materials use for air conditioning - A short review," E3S Web Conf., vol. 14, pp. $0-7, \quad 2017$, doi: 10.1051/e3sconf/20171401033.

[6] A. Abhat, "Low temperature latent heat thermal energy storage: Heat storage materials," Sol. Energy, vol. 30, no. 4, pp. 313-332, 1983, doi: 10.1016/0038-092X(83)90186-X.

[7] M. M. Farid, A. M. Khudhair, S. A. K. Razack, and S. Al-Hallaj, "A review on phase change energy storage: Materials and applications," Energy Convers. Manag., vol. 45, no. 9-10, pp. 15971615, 2004, doi: 10.1016/j.enconman.2003.09.015.

[8] D. Zhou, C. Y. Zhao, and Y. Tian, "Review on thermal energy storage with phase change materials (PCMs) in building applications," Appl. Energy, vol. 92, pp. 593-605, 2012, doi: 10.1016/j.apenergy.2011.08.025.

[9] M. M. Kenisarin and K. M. Kenisarina, "Formstable phase change materials for thermal energy storage," Renew. Sustain. Energy Rev., vol. 16, no. 4, pp. 1999-2040, 2012, doi: 10.1016/j.rser.2012.01.015.

[10] G. Li, Y. Hwang, R. Radermacher, and H. H. Chun, "Review of cold storage materials for subzero applications," Energy, vol. 51, pp. 1-17, 2013, doi: 10.1016/j.energy.2012.12.002.

[11] A. Fallahi, G. Guldentops, M. Tao, S. GranadosFocil, and S. Van Dessel, "Review on solid-solid phase change materials for thermal energy storage: Molecular structure and thermal properties," Appl. Therm. Eng., vol. 127, no. December, pp. 14271441, 2017, doi: 10.1016/j.applthermaleng.2017.08.161.

[12] S. D. Sharma, D. Buddhi, and R. L. Sawhney, "Accelerated thermal cycle test of latent heatstorage materials," Sol. Energy, vol. 66, no. 6, pp. 483-490, 1999, doi: 10.1016/S0038092X(99)00045-6.

[13] A. Sharma, S. D. Sharma, and D. Buddhi, "Accelerated thermal cycle test of acetamide, stearic acid and paraffin wax for solar thermal latent heat storage applications," Energy Convers. Manag., vol. 43, no. 14, pp. 1923-1930, 2002, doi: 10.1016/S0196-8904(01)00131-5.

[14] H. Kimura and J. Kai, "Mixtures of calcium chloride hexahydrate with some salt hydrates or anhydrous salts as latent heat storage materials," Energy Convers. Manag., vol. 28, no. 3, pp. $197-$ 200, 1988, doi: 10.1016/0196-8904(88)90021-0.

[15] A. Shukla, D. Buddhi, and R. L. Sawhney, "Thermal cycling test of few selected inorganic and organic phase change materials," Renew. Energy, vol. 33, no. 12, pp. 2606-2614, 2008, doi: 
10.1016/j.renene.2008.02.026.

[16] V. V. Tyagi and D. Buddhi, "Thermal cycle testing of calcium chloride hexahydrate as a possible PCM for latent heat storage," Sol. Energy Mater. Sol. Cells, vol. 92, no. 8, pp. 891-899, 2008, doi: 10.1016/j.solmat.2008.02.021.

[17] S. M. Hasnain, "Review on sustainable thermal energy storage technologies, part I: Heat storage materials and techniques," Energy Convers. Manag., vol. 39, no. 11, pp. 1127-1138, 1998.

[18] M. S. Dresselhaus et al., "New directions for lowdimensional thermoelectric materials," $A d v$. Mater., vol. 19, no. 8, pp. 1043-1053, 2007, doi: 10.1002/adma.200600527.

[19] S. B. Riffat and X. Ma, "Thermoelectrics: A review of present and potential applications," Appl. Therm. Eng., vol. 23, no. 8, pp. 913-935, 2003, doi: 10.1016/S1359-4311(03)00012-7.

[20] S. B. Riffat, S. A. Omer, and X. Ma, "A novel thermoelectric refrigeration system employing heat pipes and a phase change material: An experimental investigation," Renew. Energy, vol. 23, no. 2, pp. 313-323, 2001, doi: 10.1016/S09601481(00)00170-1.

[21] S. Chatterjee and K. G. Pandey, "Thermoelectric cold-chain chests for storing/transporting vaccines in remote regions," Appl. Energy, vol. 76, no. 4, pp. 415-433, 2003, doi: 10.1016/S03062619(03)00007-2.

[22] N. Putra, R. A. Koestoer, M. Adhitya, A. Roekettino, and B. Trianto, "Kendaraan Hibrid," Makara Teknol., vol. 13, no. 2, pp. 53-58, 2009.

[23] S. Pourhedayat, "Application of thermoelectric as an instant running-water cooler; experimental study under different operating conditions," Appl. Energy, vol. 229, no. August, pp. 364-374, 2018, doi: 10.1016/j.apenergy.2018.08.009.

[24] E. Cuce, T. Guclu, and P. M. Cuce, "Improving thermal performance of thermoelectric coolers (TECs) through a nanofluid driven water to air heat exchanger design: An experimental research," Energy Convers. Manag., vol. 214, no. February, p. 112893, 2020, doi: 10.1016/j.enconman.2020.112893.

[25] S. M. Pourkiaei et al., "Thermoelectric cooler and thermoelectric generator devices: A review of present and potential applications, modeling and materials," Energy, vol. 186, p. 115849, 2019, doi: 10.1016/j.energy.2019.07.179.

[26] G. Snyder and E. Toberer, "Complex Thermoelectric Materials," Nat. Mater., vol. 7, pp. 105-114, Mar. 2008, doi: 10.1038/nmat2090.

[27] G. Nolas, J. Poon, and M. Kanatzidis, "Recent
Developments in Bulk Thermoelectric Materials," MRS Bull., vol. 31, Mar. 2006, doi: 10.1557/mrs2006.45.

[28] T. Harman, M. Walsh, B. laforge, and G. Turner, "Nanostructured thermoelectric materials," $J$. Electron. Mater., vol. 34, pp. L19-L22, Jan. 2005, doi: 10.1007/s11664-005-0083-8.

[29] F. J. Disalvo, "Thermoelectric cooling and power generation," Science (80-. )., vol. 285, no. 5428, pp. 703-706, 1999, doi: 10.1126/science.285.5428.703.

[30] Y. H. Cheng and W. K. Lin, "Geometric optimization of thermoelectric coolers in a confined volume using genetic algorithms," Appl. Therm. Eng., vol. 25, no. 17-18, pp. 2983-2997, 2005, doi: 10.1016/j.applthermaleng.2005.03.007.

[31] S. Lineykin and S. Ben-Yaakov, "User-friendly and intuitive graphical approach to the design of thermoelectric cooling systems," Int. J. Refrig., vol. 30, no. 5, pp. 798-804, 2007, doi: 10.1016/j.ijrefrig.2006.12.004.

[32] H. S. Lee, "The Thomson effect and the ideal equation on thermoelectric coolers," Energy, vol. 56, pp. 61-69, 2013, doi: 10.1016/j.energy.2013.04.049.

[33] D. Zhao and G. Tan, "A review of thermoelectric cooling: Materials, modeling and applications," Appl. Therm. Eng., vol. 66, no. 1-2, pp. 15-24, 2014, doi: 10.1016/j.applthermaleng.2014.01.074.

[34] A. G. A. Nnanna, W. Rutherford, W. Elomar, and B. Sankowski, "Assessment of thermoelectric module with nanofluid heat exchanger," Appl. Therm. Eng., vol. 29, no. 2-3, pp. 491-500, 2009, doi: 10.1016/j.applthermaleng.2008.03.007.

[35] N. Putra, Yanuar, and F. N. Iskandar, "Application of nanofluids to a heat pipe liquid-block and the thermoelectric cooling of electronic equipment," Exp. Therm. Fluid Sci., vol. 35, no. 7, pp. 12741281, 2011, doi: 10.1016/j.expthermflusci.2011.04.015.

[36] W. H. Chen, C. Y. Liao, and C. I. Hung, “A numerical study on the performance of miniature thermoelectric cooler affected by Thomson effect," Appl. Energy, vol. 89, no. 1, pp. 464-473, 2012, doi: 10.1016/j.apenergy.2011.08.022.

[37] G. J. Snyder, E. S. Toberer, R. Khanna, and W. Seifert, "Improved thermoelectric cooling based on the Thomson effect," Phys. Rev. B - Condens. Matter Mater. Phys., vol. 86, no. 4, pp. 1-8, 2012, doi: 10.1103/PhysRevB.86.045202.

[38] O. Yamashita, "Effect of interface layer on the cooling performance of a single thermoelement," Appl. Energy, vol. 88, no. 9, pp. 3022-3029, 2011, 
doi: 10.1016/j.apenergy.2011.03.017.

[39] H. S. Lee, "Optimal design of thermoelectric devices with dimensional analysis," Appl. Energy, vol. 106, pp. 79-88, 2013, doi: 10.1016/j.apenergy.2013.01.052.

[40] L. Zhu and J. Yu, "Optimization of heat sink of thermoelectric cooler using entropy generation analysis," Int. J. Therm. Sci., vol. 118, pp. 168-175, 2017, doi: 10.1016/j.ijthermalsci.2017.04.015.

[41] L. Shen, L. Xiao, H. Chen, and S. Wang, "Investigation of a novel thermoelectric radiant airconditioning system," Energy Build., vol. 59, pp. 123-132, Apr. 2013, doi: 10.1016/j.enbuild.2012.12.041.

[42] M. Gillott, L. Jiang, and S. Riffat, "An investigation of thermoelectric cooling devices for small-scale space conditioning applications in buildings," Int. J. Energy Res., vol. 34, no. 9, pp. 776-786, 2010, doi: 10.1002/er.1591.

[43] T. C. Cheng, C. H. Cheng, Z. Z. Huang, and G. C. Liao, "Development of an energy-saving module via combination of solar cells and thermoelectric coolers for green building applications," Energy, vol. 36, no. 1, pp. 133-140, 2011, doi: 10.1016/j.energy.2010.10.061. 